\title{
Influência de Manejos Pós-Colheita do ARRoz IRRIGado sobre o Banco de Sementes de ARRoZ-Vermelho ${ }^{1}$
}

\author{
Influence of Post-Harvest Management of Rice Crop on Red Rice Seed Bank \\ MASSONI, P.F.S. ${ }^{2}$, MARCHESAN, E. ${ }^{3}$, GROHS, M. ${ }^{4}$, ROSO, R. ${ }^{5}$, COELHO, L.L..$^{6}$, \\ MACHADO, S.L.O. ${ }^{7}$, TELÓ, G.M. ${ }^{8}$ e DAL'COL LÚCIO, A. ${ }^{9}$
}

\begin{abstract}
RESUMO - A incorporação da palha após a colheita do arroz dificulta a redução do banco de sementes; por outro lado, favorece a decomposição da palha e, consequentemente, possibilita o preparo antecipado da área, viabilizando a semeadura do arroz no período recomendado. $\mathrm{O}$ objetivo deste trabalho foi avaliar a interferência de diferentes manejos após a colheita em áreas cultivadas com arroz irrigado na redução da viabilidade de sementes de arroz-vermelho. O delineamento experimental utilizado foi de blocos ao acaso, em parcelas subdivididas no tempo, com quatro repetições. Os tratamentos foram dispostos em esquema fatorial (7x6), sendo o fator A composto por: [1] lâmina de água permanente, [2] incorporação da palha com preparo do solo seco logo após a colheita do arroz, [3] incorporação da palha com preparo do solo alagado após a colheita, [4] incorporação da palha com o solo seco somente em julho, [5] incorporação da palha com solo alagado logo após a colheita e gradagem da área em julho com solo seco, [6] incorporação da palha com solo seco logo após a colheita e gradagem da área em julho com solo seco e [7] sem incorporação. O fator B foi composto por seis épocas de amostragem do banco de sementes quanto à presença de arroz-vermelho; a amostragem iniciou-se a partir da colheita, ocorrendo a cada 30 dias e finalizando no mês de outubro. $\mathrm{O}$ maior efeito sobre a redução do banco de sementes ocorreu quando se utilizaram implementos que incorporaram superficialmente a palha, como o rolo-faca, o qual atua sobre a quebra da dormência, a inviabilidade e o estimulo à germinação das sementes de arroz-vermelho.
\end{abstract}

Palavras-chave: Oryza sativa, preparo do solo, planta daninha.

\begin{abstract}
The incorporation of straw after rice harvest makes rice seed reduction difficult. On the other hand, it favors the decomposition of straw, enabling the preparation of the area in advance, thus allowing the preparation of the recommended planting period. The objective of this work was to assess the interference of different management techniques after harvest in rice-cultivated areas in reducing the viability of red rice seeds. The experiment was arranged in a randomized block design, in split-plots in time, with four replications. The treatments were arranged in a factorial design (7x6), consisting of factor A: [a] permanent water blade, [2] straw incorporation with dry soil tillage after rice harvest, [3] incorporation of straw with flooded soil after harvest, [4] incorporation of dry soil only in July, [5] incorporation of straw with flooded soil after harvest and area disking in July with dry soil, [6] incorporation of straw in dry soil immediately after harvest and area disking only in July with dry soil and [7] without incorporation. Factor B was composed of different timings of seed bank sampling for the presence of red rice. Sampling was initiated at harvest, occurring every thirty days until October. The greatest effect on seed bank reduction was verified when using implements that superficially incorporated the straw, such as the rolling knife, which acts on dormancy breaking, non-viability and stimulation of red rice germination.
\end{abstract}

Keywords: Oryza_sativa, soil preparation, weed.

1 Recebido para publicação em 14.8.2011 e aprovado em 23.7.2012

2 Engo-o-Agr ${ }^{\circ}$., M.Sc. em Produção Vegetal, <pfmass@hotmail.com>; ${ }^{3}$ Professora, Dra., Dep. de Fitotecnia, Universidade Federal de Santa Maria -UFSM, <emarchezan@terra.com.br>; ${ }^{4}$ Engํ-Agr ${ }^{\circ}$., M.Sc. em Produção Vegetal, <maragrohs@yahoo.com.br>; ${ }^{5}$ Aluno do Curso de Agronomia, UFSM, <rodrigoroso@yahoo.com.br>; ${ }^{6}$ Aluno do Curso de Agronomia, UFSM, < lucas_1_c@hotmail.com>; ${ }^{7}$ Professor, Dr., Dep. de Fitossanidade, UFSM, <smachado@smail.ufsm.br>; ${ }^{8}$ Aluno de doutorado em Produção Vegetal, UFSM, <gustavo.telo@yahoo.com.br>; ${ }^{9}$ Professor, Dr., Dep. de Fitotecnia, UFSM, <adlucio@pq.cnpq.br>.

Planta Daninha, Viçosa-MG, v. 31, n. 1, p. 89-98, 2013 


\section{INTRODUÇÃO}

A utilização das áreas de várzea para cultivo do arroz irrigado no Estado do Rio Grande do Sul (RS) é diversificada. O oeste do Estado tem como características a elevada produtividade e a possibilidade de intercalar o cultivo do arroz com pecuária de corte e/ou, em menor escala, cultivos alternativos com a cultura da soja ou pousio da área. Por sua vez, a região central é caracterizada por propriedades menores e com cultivo continuado de arroz irrigado na mesma área, o que dificulta o controle do arrozvermelho, principal planta daninha da cultura do arroz irrigado (Noldin et al., 2004).

Na região central, o manejo do solo e da palha após a colheita do arroz favorece a decomposição da palha, assim como corrige as imperfeições da área decorrentes da operação de colheita. Essa opção facilita as posteriores operações de preparo do solo e viabiliza a semeadura do arroz irrigado na época preferencial (outubro), o que potencializa a produtividade da cultura, visto que esta é altamente influenciada pela época de semeadura (SOSBAI, 2010). Em algumas regiões do Estado, no entanto, há dificuldade de realizar a semeadura na época preferencial, pois a má drenagem, característica dos solos de várzea, juntamente com a elevada produção de palha do arroz, dificultam o preparo antecipado da área e, consequentemente, a semeadura na época preferencial.

Associado a essa problemática, em muitas áreas há elevada infestação de arrozvermelho, devido à capacidade das sementes dessa planta daninha de permanecer viáveis no solo por longo período. Peske et al. (1997) caracterizaram a longevidade das sementes de arroz-vermelho, a qual pode apresentar percentuais de germinação inferiores a $5 \%$ após dois anos, indicando o elevado grau de dormência das sementes. Associado a isso, alterações de luminosidade, de temperatura e de umidade do solo em função da quantidade de palha podem influenciar diretamente a quebra da dormência das sementes. Entre elas, a temperatura é um dos principais fatores que regem as mudanças no banco de sementes e, consequentemente, na dormência, em campo. Ela está relacionada com a germinação de sementes, como, por exemplo, mudanças na amplitude térmica e no potencial hídrico, além da sensibilidade das sementes à luz e a temperaturas alternadas (Batlla \& BenechArnold, 2007).

Além da dormência das sementes do arrozvermelho, a persistência no solo pode ser favorecida pela distribuição das sementes no perfil do solo, devido à frequência de preparo (Lindquist \& Maxwell, 1991). Nesse sentido, a prática utilizada no manejo após a colheita do arroz pode contribuir para manutenção ou aumento do banco de sementes e, consequentemente, dificultar seu controle.

Nesse cenário, o objetivo deste trabalho foi avaliar a interferência de diferentes manejos após a colheita de arroz irrigado sobre a evolução do banco de sementes de arrozvermelho.

\section{MATERIAL E MÉTODOS}

O experimento foi instalado em campo, em área de várzea sistematizada, localizada no município de Santa Maria-RS, durante os anos de 2009 e 2010.

Para obtenção do banco de sementes, foi semeado arroz convencional (cultivar IRGA 417) nos mesmos anos de condução do ensaio, em área com histórico de infestação com arroz-vermelho. O arroz cultivado foi colhido com umidade inferior a $15 \%$, a fim de possibilitar o degrane natural do arroz-vermelho e do arroz cultivado e, consequentemente, a realimentação do banco de sementes do solo.

O delineamento experimental utilizado foi de blocos ao acaso, com parcelas subdivididas no tempo, com quatro repetições. As unidades experimentais apresentaram área total de $75 \mathrm{~m}^{2}(15 \times 5 \mathrm{~m})$, sendo os tratamentos alocados nas mesmas unidades experimentais durante os dois anos de condução do experimento, através de um esquema bifatorial (7 x 6). O fator A foi composto pelos preparos do solo após a colheita do arroz:[1] lâmina de água permanente, [2] incorporação da palha com preparo do solo seco logo após a colheita do arroz, [3] incorporação da palha com preparo do solo alagado após a colheita, [4] incorporação da palha com o solo seco em julho, [5] incorporação da palha com solo alagado logo após a colheita e gradagem da área em julho com solo seco, [6] incorporação da palha com 
solo seco logo após a colheita e gradagem da área em julho com solo seco e [7] sem incorporação.

Para o tratamento com a manutenção da lâmina de água (tratamento 1), primeiramente realizou-se a colheita do arroz cultivado no seco, e uma semana após a colheita procedeu-se à inundação da área; à medida que ocorria a redução da lâmina de água, havia reposição, mantendo-a entre 5 e $10 \mathrm{~cm}$. A drenagem das unidades experimentais foi realizada 30 dias antes da última coleta de solo (11/9/2009 e 6/9/2010).

Nos tratamentos em que se incorporou a palha após a colheita com o solo seco, utilizouse uma grade niveladora com profundidade de trabalho de 10 a $15 \mathrm{~cm}$. Para os tratamentos com incorporação da palha com solo alagado, utilizou-se um rolo-faca. Esse implemento proporciona maior contato do solo com a palha, porém mantém esta próxima à superfície do solo, com pequena incorporação: aproximadamente $3 \mathrm{~cm}$.

As datas do preparo após a colheita (preparo inicial) para o primeiro e segundo anos foram 11/5/2009 (10 dias após a colheita) e 3/5/2010 (8 dias após a colheita). Os manejos de julho foram realizados em 29/7/2009 e 10/8/2010, para o primeiro e segundo anos, respectivamente.

$\mathrm{O}$ fator $\mathrm{B}$ foi representado pelos momentos de coleta de amostras do banco de sementes de arroz-vermelho após a colheita, sendo a primeira coleta realizada no dia da colheita e as subsequentes, a cada 30 dias $(0,30,60,90$, 120 e 150 dias após a colheita - DAC). Inicialmente, foram demarcadas duas áreas amostrais $(0,25 \times 0,25 \mathrm{~m})$, em cada unidade experimental. Após a coleta do solo, foi efetuada a média das duas áreas amostrais, para composição do banco de sementes. As coletas de solo foram feitas no perfil do solo, de 0 a $10 \mathrm{~cm}$ de profundidade. Além disso, para os tratamentos "lâmina de água permanente" e "sem preparo do solo", as sementes que se encontravam na superfície foram coletadas manualmente, bem como as que já se encontravam germinadas, pois nesses tratamentos não havia revolvimento do solo. O termo "sementes germinadas" refere-se às plântulas de arroz-vermelho provenientes do banco de sementes. À medida que o solo era coletado da área demarcada, demarcava-se novamente outra área para a coleta posterior.

O volume de solo analisado para cada tratamento em cada data de coleta foi composto de, aproximadamente, $0,05 \mathrm{~m}^{3}$ de solo. O número de sementes encontrado em cada amostra foi representado como porcentagem do total de sementes de cada amostra. Dessa forma, o somatório das sementes dormentes e inviáveis e de plântulas de arroz-vermelho totalizava $100 \%$.

As sementes encontradas foram submetidas à análise de viabilidade através do teste de tetrazólio (concentração de $0,2 \%$ ), segundo as Regras de Análises de Sementes (Brasil, 2009), sendo classificadas em viáveis e não viáveis. As sementes viáveis foram consideradas dormentes. Com isso, o banco de sementes foi estratificado da seguinte forma: sementes inviáveis e germinadas, as quais foram denominadas plântulas, e sementes viáveis, que foram consideradas dormentes.

As variáveis analisadas de porcentagem de sementes dormentes, inviáveis e plântulas de arroz-vermelho foram submetidas ao teste das pressuposições do modelo matemático (normalidade e homogeneidade das variâncias pelo teste de Liliefor). Para o fator A, as médias dos tratamentos foram comparadas pelo teste de Tukey $(\mathrm{p} \leq 0,05)$ e para o fator $\mathrm{B}$ foram ajustadas equações pela análise de regressão. Os anos foram avaliados separadamente, e os dados, submetidos à análise de variância pelo teste F.

Para os resultados que não atenderam às pressuposições de normalidade e homogeneidade das variâncias foram utilizadas transformações, em que para sementes dormentes e inviáveis utilizou-se $y t=\sqrt{y}$ e, para os demais dados de porcentagem de plantas, $y t=\sqrt{(y)+0,5}$.

\section{RESULTADOS E DISCUSSÃO}

\section{Sementes da superficie do solo}

Para as sementes da superfície do solo, no tratamento com lâmina permanente de água, ocorreu redução significativa da porcentagem 
de sementes dormentes no decorrer do período avaliado (150 dias), durante os anos de 2009 e 2010 (Figura 1A). Esse resultado é reflexo da retirada da água, o que proporcionou condições ambientais para que as sementes germinas-sem, concentrando essa germinação a partir dos 120 dias após a colheita (DAC). Essa redução na dormência foi de $69 \%$ entre a primeira e a última coleta (150 DAC), para o primeiro ano, e de $48 \%$ para o segundo ano (Tabela 1 ).

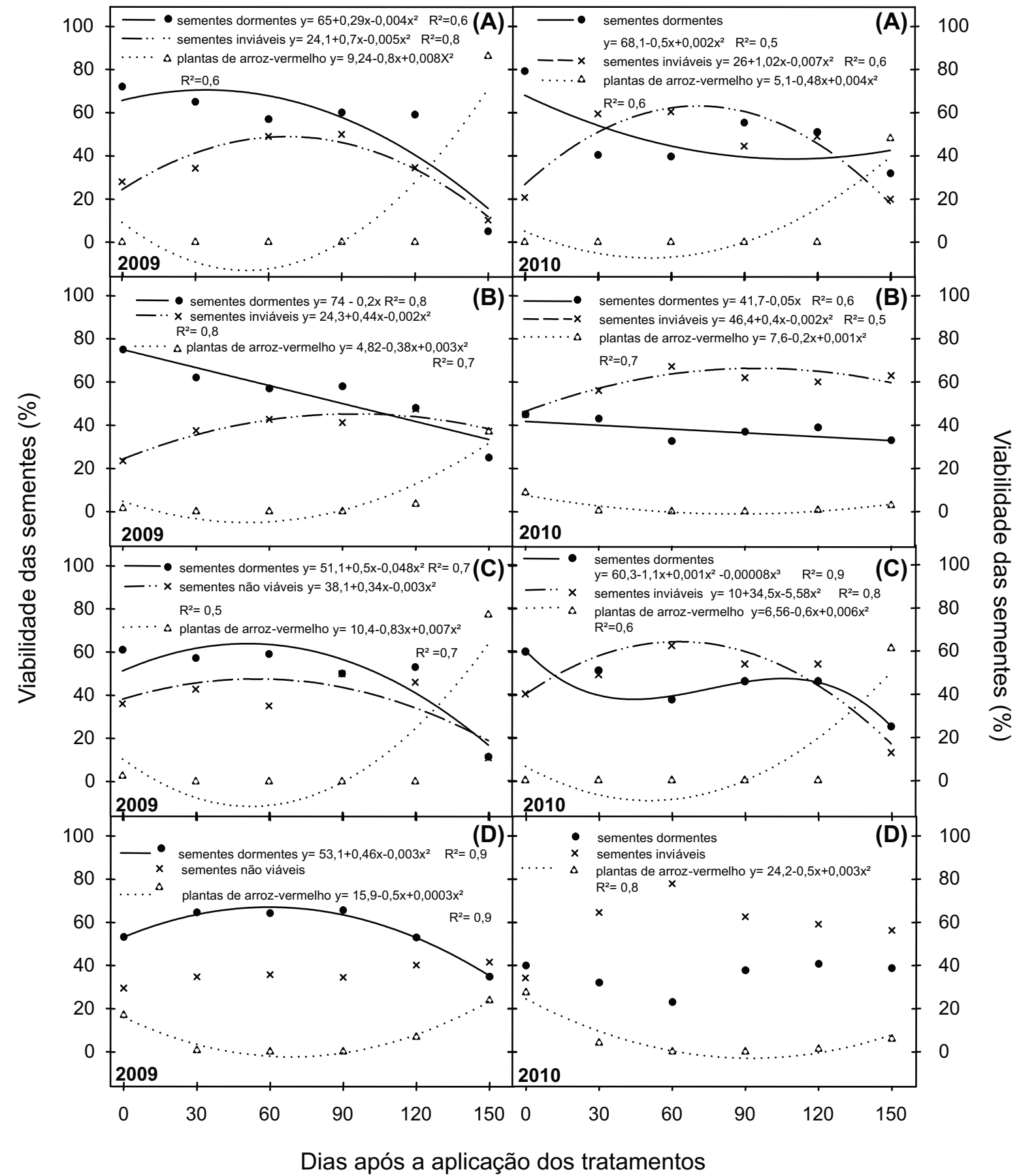

Figura 1 - Porcentagem de sementes dormentes, inviáveis e plantas de arroz-vermelho nos tratamentos com lâmina de água permanente nos anos de 2009 e 2010 na superficie do solo (A) e na camada de 0-10 cm (C) no tratamento sem preparo de solo nos anos 2009 e 2010 na superficie do solo (B) na camada de 0-10 cm (D). Santa Maria-RS, 2012 
Tabela 1 - Porcentagem de sementes dormentes, inviáveis e plântulas de arroz-vermelho na superfície do solo durante o período de coleta nos anos de 2009 e 2010, nos tratamentos com lâmina permanente de água, com preparo do solo seco em julho e sem preparo de solo. Santa Maria-RS, 2012

\begin{tabular}{|c|c|c|c|c|c|c|}
\hline \multirow{3}{*}{ Tratamento } & \multicolumn{6}{|c|}{ Dias após a aplicação dos tratamentos } \\
\hline & \multicolumn{3}{|c|}{2009} & \multicolumn{3}{|c|}{2010} \\
\hline & 0 & 120 & 150 & 0 & 120 & 150 \\
\hline \multicolumn{7}{|c|}{ Sementes dormentes de arroz-vermelho na superfície do solo (\%) } \\
\hline Lâmina de água & $72^{\mathrm{ns}}$ & $55^{\mathrm{ns}}$ & $3 \mathrm{~b}$ & $79^{\text {ns }}$ & $51^{\mathrm{ns}}$ & $31 b^{*}$ \\
\hline Sem preparo do solo & 74 & 49 & $25 \mathrm{a}$ & 45 & 39 & $33 \mathrm{a}$ \\
\hline $\mathrm{CV}(\%)$ & \multicolumn{3}{|c|}{29} & \multicolumn{3}{|c|}{30} \\
\hline \multicolumn{7}{|c|}{ Sementes inviáveis de arroz-vermelho na superfície do solo (\%) } \\
\hline Lâmina de água & $28^{\mathrm{ns}}$ & $45^{\mathrm{ns}}$ & $11 \mathrm{~b}$ & $21^{\mathrm{ns}}$ & $49^{\text {ns }}$ & $21 \mathrm{~b}$ \\
\hline Sem preparo do solo & 24 & 47 & $38 \mathrm{a}$ & 46 & 60 & $64 \mathrm{a}$ \\
\hline $\mathrm{CV}(\%)$ & \multicolumn{3}{|c|}{29} & \multicolumn{3}{|c|}{23} \\
\hline \multicolumn{7}{|c|}{ Plântulas de arroz-vermelho na superfície do solo (\%) } \\
\hline Lâmina de água & $0^{\mathrm{ns}}$ & $0^{\mathrm{ns}}$ & $86 \mathrm{a}$ & $0^{\mathrm{ns}}$ & $0^{\mathrm{ns}}$ & $48 \mathrm{a}$ \\
\hline Sem preparo do solo & 2 & 4 & $37 \mathrm{~b}$ & 9 & 0,6 & $2,9 \mathrm{~b}$ \\
\hline $\mathrm{CV}(\%)$ & \multicolumn{3}{|c|}{29} & \multicolumn{3}{|c|}{53} \\
\hline
\end{tabular}

Embora o período pós-colheita seja de temperaturas baixas, dificultando a superação da dormência, ele foi suficiente para superação da dormência das sementes que permaneceram sob lâmina de água. Em ambiente anaeróbico, algumas alterações podem ocorrer no metabolismo das sementes, podendo levar à superação da dormência. Entre essas alterações está o aumento na produção de etanol nas células (Magneschi et al., 2009); a maior concentração de etanol nelas e sua relação de lipofilicidade aumentam a desordem na parede celular, a qual resulta em maior fluidificação da membrana, o que é comparável ao efeito de aumento de temperatura (Hallett \& Bewley, 2002). Dessa forma, essas modificações que ocorreram na membrana em ambiente anaeróbico podem ter favorecido a superação da dormência nesse tratamento.

Esse resultado é de extrema importância no controle do arroz-vermelho, porém devemse levar em consideração dois aspectos: a drenagem foi realizada muito próximo à semeadura do arroz, o que pode dificultar o preparo do solo e inviabilizar a semeadura no início da época preferencial; e esse sistema não é ambientalmente sustentável, pois a manutenção da lâmina de água foi realizada durante toda a entressafra, elevando os custos.
O tratamento sem preparo de solo (Figura 1B) apresentou redução linear na porcentagem de sementes dormentes no decorrer dos 150 DAC, com redução de $49 \%$ entre a primeira (0 DAC) e a última coleta (150 DAC). Nesse tratamento, as sementes dormentes transformaram-se em sementes inviáveis e em plântulas de arroz-vermelho. A germinação das sementes distribuiu-se entre o início (maio - 30 DAC) e o final do período das avaliações (outubro), possivelmente em razão das temperaturas mais elevadas ocorridas nesses momentos. Além disso, a germinação que ocorreu aos $30 \mathrm{DAC}$ pode estar relacionada com os diferentes graus de dormência das sementes que se encontram na mesma planta. Segundo Finch-Savage (2006), a dormência pode estar associada à existência de diferenças de germinabilidade das sementes em função da posição delas na panícula. Possivelmente, as sementes de arroz-vermelho que germinaram nos primeiros 30 DAC foram sementes que degranaram precocemente e sofreram maior influência das oscilações térmicas e de umidade na superficie do solo, estimulando assim a germinação.

Deve-se salientar a grande quantidade de sementes inviáveis nesse tratamento, o qual atingiu valores próximos a $38 \%$ no primeiro ano e $64 \%$ no segundo ano, para as sementes 
da superficie do solo. Isso ocorre quando as sementes permanecem sobre a superficie e ficam expostas às oscilações de temperatura e umidade, ou até mesmo a ataque de fungos e insetos, que podem atuar diretamente na sua inviabilização. Em trabalho conduzido por Marchezan et al. (2003), 99\% das sementes de arroz-vermelho que permaneceram na superficie perderam sua viabilidade.

Estudos desenvolvidos por Vidotto \& Ferrero (2000) revelaram que as sementes de arrozvermelho que permanecem em campo atingem o máximo potencial germinativo aos 153 DAC em ambiente seco. Por outro lado, a germinação de uma população de arroz-vermelho que permaneceu sob lâmina de água apresentou 95\% de germinação após 136 DAC (Fogliatto et al., 2010).

Para o segundo ano, houve redução significativa na dormência das sementes, sendo menor que a do ano anterior. Possivelmente, esse fato seja reflexo das condições climáticas experimentadas pelas sementes ainda quando ligadas à planta-mãe, já que, ao 0 DAC 45\% das sementes estavam dormentes, indicando alguma alteração no período anterior ao da coleta inicial. Além disso, essa alteração também pode ter proporcionado dormência mais acentuada, ocasionando maior dificuldade na sua superação e, consequentemente, menor redução da dormência ao final dos 150 DAC.

\section{Sementes na camada de $0-10 \mathrm{~cm}$}

Para o tratamento com lâmina de água permanente (Figura 1C), durante o período póscolheita, o comportamento das sementes dormentes e inviáveis e de plantas de 0 a $10 \mathrm{~cm}$ foi semelhante ao daquelas que permaneceram na superfície do solo nos dois anos, sendo evidente o efeito da água nas sementes em diferentes profundidades: aos 150 DAC, após a retirada da água, foram observados $77 \mathrm{e}$ $61 \%$ de sementes germinadas para o primeiro e segundo anos, respectivamente (Tabela 2).

O tratamento sem preparo do solo foi o segundo com maior porcentagem de plântulas, aos 0 e 150 DAC (Figura 1D). Esse comportamento pode estar relacionado com a distribuição das sementes no perfil do solo: as sementes que estavam mais próximas da superficie tiveram condições favoráveis para germinar. É importante destacar que, nesse tratamento, a redução da dormência foi significativamente maior nas sementes que se encontravam na superficie do solo.

A utilização de um manejo de solo com equipamentos que incorporam a palha a maiores profundidades $(1015 \mathrm{~cm})$ reduz o efeito sobre as sementes dormentes e inviáveis de arroz-vermelho, pois nenhuma equação ajustou-se aos resultados obtidos (Figura 2A). Isso ocorre porque, quando a semente é incorporada a maiores profundidades, fica menos exposta a oscilações de umidade e temperatura, as quais poderiam inviabilizá-la ou acelerar sua germinação, tanto no tratamento em que foi realizada a incorporação logo após a colheita, como naquele em que a incorporação ocorreu em julho (Figura 2B), concordando com os resultados de Noldin et al. (2006).Quando se utilizou essa operação por duas vezes na entressafra, logo após a colheita e em julho (Figura 2C), obteve-se um nivel de inviabilização das sementes de $22 \%$. Isso ocorre porque, ao se submeter o solo a uma operação de gradagem, ocorre estímulo à entrada de oxigênio e modificação da temperatura do perfil do solo, afetando as sementes. Segundo Chung \& Paek al. (2003), quando se mantém a semente de arroz-vermelho em temperatura oscilante de 10 a $20{ }^{\circ} \mathrm{C}$ durante os meses de inverno, 93\% das sementes são estimuladas a germinar, porém, quando mantidas em temperatura constante de $15{ }^{\circ} \mathrm{C}$, a porcentagem encontrada é inferior. Além disso, o revolvimento do solo proporciona maior difusão de gases essenciais para germinação, além de as sementes sofrerem estímulos luminosos nos seus fitocromos, enquanto as sementes velhas, que já haviam superado a dormência, recebem os estímulos necessários à germinação e passam de sementes dormentes a plântulas ou a sementes inviáveis. Já as sementes que foram submetidas apenas a um preparo de solo não recebem estímulo suficiente para germinar. O problema é que esse manejo realimenta continuamente o perfil com novas sementes de arrozvermelho, impedindo o esgotamento do banco de sementes.

Quando se adotam implementos que incorporam a palha superficialmente (em torno de $3 \mathrm{~cm}$ ), como é o caso do rolo-faca, o efeito sobre 
Tabela 2 - Porcentagem de sementes dormentes, inviáveis e plântulas de arroz-vermelho na camada de solo de 0-10 cm de profundidade nos diferentes manejos pós-colheita aos 0, 120 e 150 dias após aplicação dos tratamentos, nos anos de 2009 e 2010. Santa Maria-RS, 2012

\begin{tabular}{|c|c|c|c|c|c|c|}
\hline \multirow{3}{*}{ Tratamento } & \multicolumn{6}{|c|}{ Dias após a aplicação dos tratamentos } \\
\hline & \multicolumn{3}{|c|}{2009} & \multicolumn{3}{|c|}{2010} \\
\hline & 0 & 120 & 150 & 0 & 120 & 150 \\
\hline \multicolumn{7}{|c|}{ Sementes dormentes de arroz-vermelho do banco de sementes $0-10 \mathrm{~cm}(\%)$} \\
\hline Lâmina de água & $61^{\mathrm{ns}}$ & $53^{\text {ns }}$ & $11 \mathrm{~b}$ & $59^{\text {ns }}$ & $46 a^{*}$ & $25^{\mathrm{ns}}$ \\
\hline Preparo pós-colheita com solo seco & 68 & 63 & $48 \mathrm{a}$ & 48 & $29 \mathrm{~b}$ & 39 \\
\hline Preparo pós-colheita com solo alagado & 61 & 56 & $41 \mathrm{a}$ & 56 & $29 \mathrm{~b}$ & 34 \\
\hline Preparo solo seco em julho & 50 & 57 & $43 \mathrm{a}$ & 46 & $39 \mathrm{ab}$ & 39 \\
\hline $\begin{array}{l}\text { Preparo pós-colheita com solo alagado + preparo em } \\
\text { julho com solo seco }\end{array}$ & 59 & 62 & $37 \mathrm{a}$ & 55 & $37 \mathrm{ab}$ & 43 \\
\hline Preparo pós-colheita e em julho com solo seco & 67 & 58 & $40 \mathrm{a}$ & 38 & $32 \mathrm{~b}$ & 50 \\
\hline Sem preparo do solo & 54 & 53 & $34 \mathrm{a}$ & 40 & $40 \mathrm{ab}$ & 38 \\
\hline $\mathrm{CV}(\%)$ & \multicolumn{3}{|c|}{25} & \multicolumn{3}{|c|}{39} \\
\hline \multicolumn{7}{|c|}{ Sementes inviáveis de arroz-vermelho do banco de sementes $0-10 \mathrm{~cm}(\%)$} \\
\hline Lâmina de água & $36^{\mathrm{ns}}$ & $46^{\mathrm{ns}}$ & $11 \mathrm{~b}$ & $40^{\mathrm{ns}}$ & $54 \mathrm{ab}$ & $13 \mathrm{~b}$ \\
\hline Preparo pós-colheita com solo seco & 31 & 35 & $47 \mathrm{a}$ & 41 & $70 \mathrm{a}$ & $59 \mathrm{a}$ \\
\hline Preparo pós-colheita com solo alagado & 36 & 41 & $46 \mathrm{a}$ & 41 & $70 \mathrm{a}$ & $62 \mathrm{a}$ \\
\hline Preparo solo seco em julho & 48 & 39 & $49 \mathrm{a}$ & 48 & $48 \mathrm{ab}$ & $51 \mathrm{a}$ \\
\hline $\begin{array}{l}\text { Preparo pós-colheita com solo alagado + preparo em } \\
\text { julho com solo seco }\end{array}$ & 40 & 32 & $48 \mathrm{a}$ & 42 & $58 \mathrm{ab}$ & $52 \mathrm{a}$ \\
\hline Preparo pós-colheita e em julho com solo seco & 32 & 40 & $55 \mathrm{a}$ & 56 & $61 \mathrm{ab}$ & $42 \mathrm{a}$ \\
\hline Sem preparo do solo & 29 & 40 & $42 \mathrm{a}$ & 33 & $58 \mathrm{ab}$ & $55 \mathrm{a}$ \\
\hline $\mathrm{CV}(\%)$ & \multicolumn{3}{|c|}{27} & \multicolumn{3}{|c|}{27} \\
\hline \multicolumn{7}{|c|}{ Plantas de arroz-vermelho do banco de sementes $0-10 \mathrm{~cm} \mathrm{( \% )}$} \\
\hline Lâmina de água & $2,6 \mathrm{~b}$ & $0,0 \mathrm{c}$ & $77 \mathrm{a}$ & $0,0 \mathrm{c}$ & $0,0 \mathrm{c}$ & $61,0 \mathrm{a}$ \\
\hline Preparo pós-colheita com solo seco & $0,2 \mathrm{~b}$ & $0,7 \mathrm{bc}$ & $4,8 \mathrm{c}$ & $9,7 \mathrm{~b}$ & $0,7 \mathrm{bc}$ & $1,7 \mathrm{c}$ \\
\hline Preparo pós-colheita com solo alagado & $3,1 \mathrm{~b}$ & $2,7 \mathrm{abc}$ & $12,3 \mathrm{c}$ & $3,0 \mathrm{bc}$ & $0,0 \mathrm{c}$ & $2,5 \mathrm{c}$ \\
\hline Preparo solo seco em julho & $1,5 \mathrm{~b}$ & $3,1 \mathrm{abc}$ & $7,8 \mathrm{c}$ & $5,7 \mathrm{~b}$ & $13,2 \mathrm{a}$ & $9,7 \mathrm{~b}$ \\
\hline $\begin{array}{l}\text { Preparo pós-colheita com solo alagado + preparo em } \\
\text { julho com solo seco }\end{array}$ & $0,6 \mathrm{~b}$ & $5,2 \mathrm{ab}$ & $14,9 \mathrm{bc}$ & $2,7 \mathrm{bc}$ & $4,5 \mathrm{abc}$ & $4,5 \mathrm{bc}$ \\
\hline Preparo pós-colheita e em julho com solo seco & $0,6 \mathrm{~b}$ & $1,8 \mathrm{abc}$ & $5,4 \mathrm{c}$ & $5,0 \mathrm{~b}$ & $6,7 \mathrm{ab}$ & $7,5 \mathrm{bc}$ \\
\hline Sem preparo do solo & $16,9 \mathrm{a}$ & $6,9 \mathrm{a}$ & $23,8 \mathrm{~b}$ & $27,0 \mathrm{a}$ & $1,2 \mathrm{bc}$ & $6,0 \mathrm{bc}$ \\
\hline $\mathrm{CV}(\%)$ & \multicolumn{3}{|c|}{47} & \multicolumn{3}{|c|}{32} \\
\hline
\end{tabular}

* Médias seguidas da mesma letra minúscula na coluna não diferem pelo teste de Tukey $(\mathrm{P} \leq 0,05)$. ${ }^{\text {ns }}$ Teste $\mathrm{F}$ não significativo ( $\left.\mathrm{p} \leq 0,05\right)$.

a fisiologia das sementes pode ser grande (Figura 3). Quando se realizou o preparo logo após a colheita (preparo após a colheita com solo alagado), houve comportamento quadrático na redução da dormência das sementes, tornando-as inviáveis a partir dos 120 DAC e estimulando o surgimento de plântulas (Figura 3A). Contudo, ao ser realizada uma operação com a grade adicionalmente a esse preparo, em julho (Figura 3B), o efeito de aeração do solo e estímulo à germinação e/ou indução à inviabilização das sementes continuou a ser benéfico, porém em menor amplitude.

Em determinados cenários que apresentem elevada precipitação, convém adotar manejos do solo que permitam a incorporação superficial da palha com solo alagado, pois ele possibilita que as sementes sejam mantidas mais próximas da superfície, em um ambiente favorável à germinação e à superação da 




Figura 2 - Porcentagem de sementes dormentes, inviáveis e plantas de arroz-vermelho na camada de 0-10 cm de profundidade nos tratamentos com preparo de solo seco após a colheita (A), preparo em julho (B) e após a colheita e em julho com solo seco (C), nos anos de 2009 e 2010. Santa Maria-RS, 2012.

dormência, além de possibilitar operações mecanizadas para a semeadura do arroz no período preferencial.

O tratamento com permanência de lâmina de água foi o mais eficaz na redução da dormência das sementes $(11 \%)$, porém é pequeno seu efeito sobre a inviabilização destas, na profundidade de $0-10 \mathrm{~cm}$. Além disso, este tratamento diferiu dos demais apenas aos 150 DAC. Apesar de seus efeitos benéficos sobre as sementes de arroz-vermelho, é um tratamento inviável do ponto de vista ambiental.
A partir dos 120 dias após a aplicação dos tratamentos, os efeitos na redução da dormência, inviabilização das sementes e germinação começaram a ser mais efetivos. O preparo com o solo seco após a colheita e o preparo do solo seco em julho mantiveram a dormência e não apresentaram efeito na inviabilização das sementes.

$\mathrm{O}$ tratamento mais eficiente na redução do banco de sementes de arroz-vermelho foi o preparo após a colheita com solo alagado, pois ele atua na redução da dormência, aumento de sementes inviáveis e estímulo à 


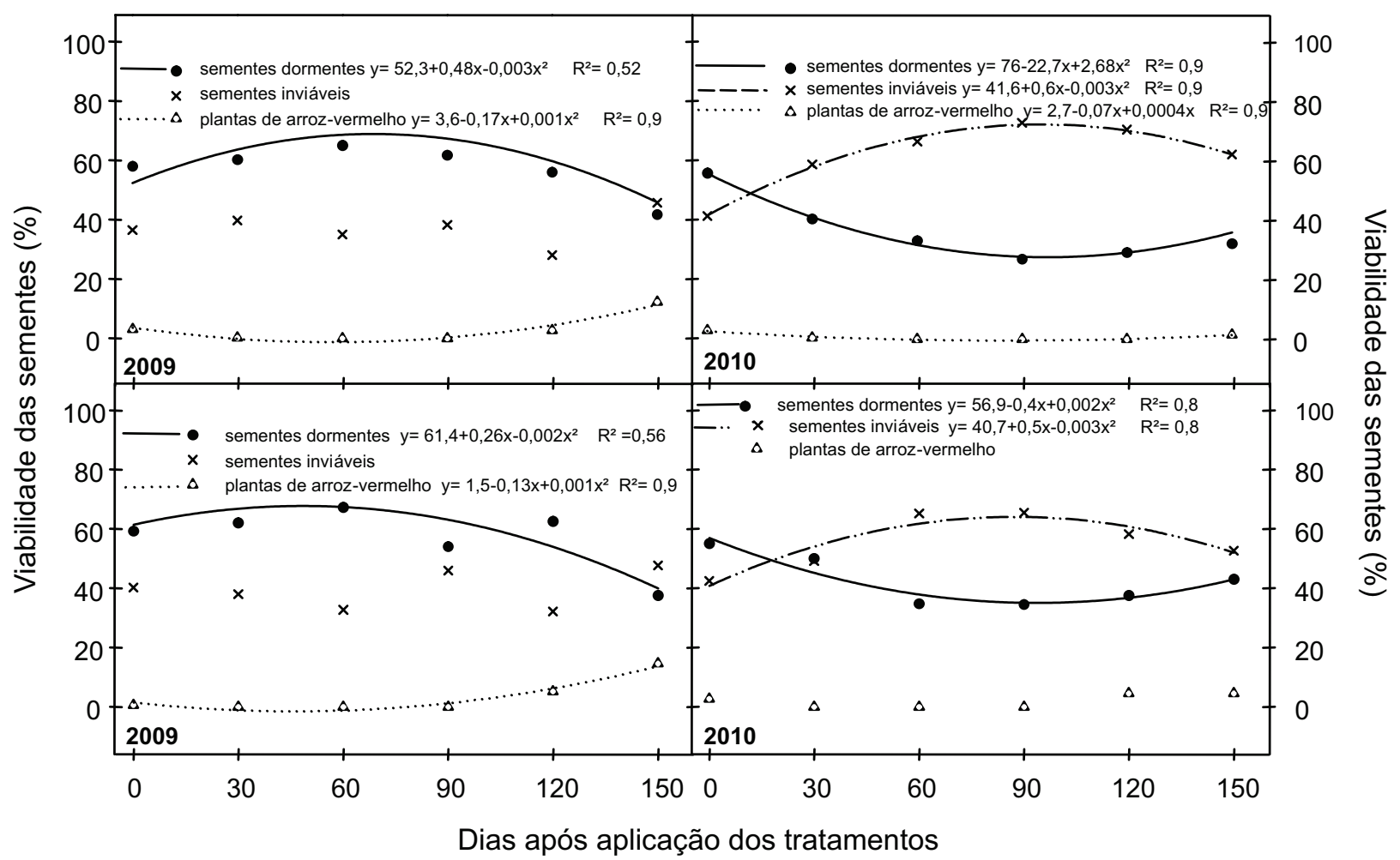

Figura 3 - Porcentagem de sementes dormentes, inviáveis e plantas de arroz-vermelho na camada de 0 - $10 \mathrm{~cm}$ de profundidade nos tratamentos com preparo após a colheita com solo alagado (A) e após a colheita com solo alagado e em julho com solo seco (B), nos anos de 2009 e 2010. Santa Maria-RS, 2012.

germinação, além de permitir o preparo antecipado da área.

\section{LITERATURA CITADA}

BATLLA, D.; BENECH-ARNOLD, R. L. Predicting changes in dormancy level in weed seed soil banks: implications for weed management. Crop Protec., v. 26, n. 1, p. 189-197, 2007.

BIRD, J. A. et al. Long-term studies find benefits, challenges in alternative rice straw management, Calif. Agric., v. 56, n. 2 , p. $69-75,2002$.

BRASIL. Ministério da Agricultura, Pecuária e Abastecimento. Regras para análise de sementes. Brasília: 2009. 399 p.

CHUNG, N. J.; PAEK, N. C. Photoblastism and ecophysiology of seed germination in weedy rice. Agron J., v. 95, n. 1, p. $184-190,2003$.

FINCH-SAVAGE W.E.; LEUBNER-METZGER, G. Seed dormancy and the control of germination. New Phytol., v. 171, n. 3 , p. 501-523, 2006.
FOGLIATTO, S. et al. Effects of winter flooding on weedy rice (Oryza sativa L.). Crop Protec., v. 29, n. 11, p. 1232-1240, 2010.

HALLETT, B. P.; BEWLEY, J. D. Membranes and seed dormancy: beyond the anesthetic hypothesis. Seed Sci. Res., v. 12, n. 2, p. 69-82, 2002.

LINDQUIST, J. L.; MAXWELL, B. D. The horizontal dispersal pattern of weed seed surrogates by farms machinery. Weed Sci., v. 46, p. 108-109, 1991.

MAGNESCHI, L.; PERATA, P. Review: rice germination and seedling growth in the absence of oxygen. Ann. Bot., v. 103, n. 2, p. 181-196, 2009.

MARCHEZAN, E. et al. Dinâmica do banco de sementes de arroz-vermelho afetado pelo pisoteio bovino e tempo de pousio da área.Planta Daninha, v. 21, n. 1, p. 55-62, 2003.

NOLDIN, J. A. Desempenho de populações híbridas $\mathrm{f} 2$ de arroz-vermelho (Oryza sativa) com arroz transgênico (O. sativa) resistente ao herbicida amônio-glufosinate1. Planta Daninha, v. 22, n. 3, p. 381-395, 2004.

NOLDIN, J. A. Seed longevity of red rice ecotypes buried in soil. Planta Daninha, v. 24, n. 4, p. 611-620, 2006. 
PESKE, S. T. et al. Sobrevivência de sementes de arrozvermelho depositadas no solo. R. Bras. Agroci., v. 3, n. 1, p. 17-22, 1997.

SOCIEDADE SUL-BRASILEIRA DE ARROZ IRRIGADO - SOSBAI. Arroz Irrigado: recomendações técnicas da pesquisa para o Sul do Brasil. In: REUNIÃO TÉCNICA DA CULTURA DO ARROZ IRRIGADO, 28., Bento Gonçalves, 2010. Porto Alegre: 2010. $188 \mathrm{p}$
SCHWANKE, A. M. L. et al. Avaliação de germinação e dormência de ecótipos de arroz-vermelho. Planta Daninha, v. 26, n. 3 , p. $497-505,2008$

VIDOTTO, F.; FERRERO, A. Germination behavior of red rice (Oryza sativa L.) seeds in field and laboratory conditions. Agronomie, v. 20, n. 4, p. 375-382, 2000 . 